\title{
Inflammatory bowel diseases in Indo-Canadians with and without antineutrophil cytoplasmic autoantibodies
}

\author{
Hugh James Freeman MD
}

HJ Freeman. Inflammatory bowel diseases in Indo-Canadians with and without antineutrophil cytoplasmic autoantibodies. Can J Gastroenterol 2000;14(1):21-26. A sequentially evaluated cohort of Indo-Canadians with either ulcerative colitis or Crohn's disease were prospectively examined for antineutrophil cytoplasmic autoantibodies (ANCA). Of 84 patients, 62 had ulcerative colitis and 22 had Crohn's disease. About one-third were born in Canada, and two-thirds were migrants from India or other countries, particularly East African nations. There was a disease-based and geographically based male predominance. The mean age of Canadian-born patients was significantly less than that of those born in other countries. Moreover, for migrants, the mean duration of residence in Canada before developing disease was 8.9 years for Crohn's disease patients and 13.5 years for ulcerative colitis patients. Moderate to severe disease was present; virtually all those with Crohn's disease had colonic involvement, and most of those with ulcerative colitis had extensive colonic disease. Overall, 40 of 84 (48\%) were seropositive for ANCA, including a majority of those with ulcerative colitis but not Crohn's disease. In addition, eight had cytoplasmic ANCA, a reported seromarker for extensive colitis. Seropositive and seronegative patients were similar in age, sex, birth or duration of residence in Canada, site and severity of disease, familial history and complications, including pouchitis. This study supports the view that these diseases arise in individuals with a genetic predisposition following exposure to some, as yet unknown, environmental factor.

Key Words: Antineutrophil cytoplasmic autoantibodies; Crohn's disease; Granulocytes; Inflammatory bowel disease; Ulcerative colitis

\section{Les maladies inflammatoires de l'intestin chez} les Indo-Canadiens présentant ou non l'auto-anticorps antineutrophile cytoplasmique

RÉSUMÉ : Une cohorte d'Indo-Canadiens souffrant de colite ulcéreuse ou de maladie de Crohn traités en séquence a été examinée de façon prospective pour le dépistage de l'auto-anticorps antineutrophile cytoplasmique (ou ANCA). Parmi les 84 patients, 62 souffraient de colite ulcéreuse et 22 de maladie de Crohn. Environ le tiers étaient nés au Canada et les deux tiers provenaient de l'Inde ou d'autres pays, particulièrement d'Afrique de l'Est. On a noté une prédominance du sexe mâle selon la maladie et l'origine géographique. L'âge moyen des patients nés au Canada était significativement moindre que celui des patients nés ailleurs. De plus, pour les immigrants, la durée moyenne de résidence au Canada avant que la maladie ne se déclare était de 8,9 ans dans le cas de la maladie de Crohn et de 13,5 ans dans le cas de la colite ulcéreuse. La maladie était présente à un stade modéré à grave; pour ainsi dire tous les patients atteints de maladie de Crohn présentaient une atteinte du côlon et la plupart de ceux qui souffraient de colite ulcéreuse présentaient une importante atteinte colique. De façon globale, 40 sujets sur 84 (48\%) étaient séropositifs à l'égard de l'ANCA, y compris la majorité de ceux qui souffraient de colite ulcéreuse, mais non de maladie de Crohn. De plus, huit présentaient des ANCA cytoplasmiques, séromarqueurs de la colite étendue. Les patients séropositifs et séronégatifs étaient semblables sur le plan de l'âge, du sexe, de la naissance ou de la durée de leur résidence au Canada, de la localisation et de la gravité de la maladie, des antécédents familiaux et des complications, y compris la pochite. Cette étude appuie l'hypothèse selon laquelle ces maladies se manifestent chez des patients qui ont une prédisposition génétique, après exposition à certains facteurs environnementaux encore inconnus.

Department of Medicine (Gastroenterology), University of British Columbia, Vancouver, British Columbia

Correspondence and reprints: Dr Hugh Freeman, ACU F-137, Vancouver Hospital (UBC Site), 2211 Wesbrook Mall, Vancouver,

British Columbia V6T 1W5. Telephone 604-822-7216, fax 604-822-7236

Received for publication November 9, 1998. Accepted December 30, 1998 
$\mathrm{P}$ revious studies have demonstrated that some antineutrophil cytoplasmic autoantibodies (ANCA) may be detected in patients with inflammatory bowel disorders, particularly in those with ulcerative colitis (1). Recently, in a prospective study of 500 Canadian patients with inflammatory bowel disease (IBD) who were evaluated at the University of British Columbia, 38.8\% were positive for ANCA $66.3 \%$ with ulcerative colitis and $11.9 \%$ with Crohn's disease (2). In addition, this seromarker persisted in patients with ulcerative colitis, even after proctocolectomy (3). Occasionally, this seromarker may be detected with other forms of IBD, specifically microscopic forms of colitis, including collagenous or lymphocytic colitis, with or without celiac disease (4). Although a specific subclass, the atypical perinuclear ANCA ( $\mathrm{p}$-ANCA), are often present if there is colonic disease, occasionally patients with Crohn's disease localized only to the small bowel may also be positive (5). In a more recent study, the presence of a relatively unique subclass, the so-called cytoplasmic ANCA (c-ANCA) typically reported in Wegener's granulomatosis, was observed in a group of 18 patients with extensive colitis (6). This subclass was not common, occurring in an estimated $2 \%$ of patients with IBD at this centre. Interestingly, significant numbers of patients with c-ANCA (ie, almost half) were Indo-Canadians.

To evaluate these disorders further in the Indo-Canadian population of metropolitan Vancouver, British Columbia, the clinical features of a cohort of 84 patients were prospectively evaluated. In this analysis, characteristics of the population cohort and features of their diseases were detailed. Also, the detection rates of different types of ANCA within this cohort were defined.

The Indo-Canadian population in metropolitan Vancouver is geographically heterogeneous in its origins. In addition to those born in Canada, individuals have migrated from the Indian subcontinent and from other countries, particularly from East African nations such as Uganda. As a result, the opportunity to explore the geographical impact on this population was provided. Finally, seropositive and seronegative status were compared in Indo-Canadians with IBD.

\section{PATIENTS AND METHODS}

Patient groups: Each patient had an established diagnosis of idiopathic ulcerative colitis or Crohn's disease in the small and/or large intestine based on clinical, radiological, endoscopic and histological criteria, and negative microbiological studies (7). Ulcerative colitis was diagnosed when a diffuse inflammatory process involving the rectum and extending proximally within the colon was present. As in previously reported studies $(2,6)$, disease extent and site were classified as 'distal disease' if inflammatory changes were localized in the distal $60 \mathrm{~cm}$ based on colonoscopic visualization as well as endoscopic mucosal biopsy, or as 'extensive disease' if inflammatory changes were over $60 \mathrm{~cm}$. Crohn's disease was diagnosed from colonoscopic and histological studies showing a segmental or patchy inflammatory process within the colorectum, distal small intestine or both, often with gran- ulomatous changes. In addition, the upper gastrointestinal tract was evaluated with the use of radiological, endoscopic and histological studies. Surgical material, if available, was also examined. During the course of this study, no other form of idiopathic IBD was observed, including the microscopic forms of colitis (lymphocytic or collagenous colitis).

All patients in this prospective study were of South Asian descent, residents of the metropolitan area of Vancouver, British Columbia, and seen by the investigator for clinical evaluation during the 46-month period from January 1995 to October 1998, inclusive. Of these 84 patients, 42 (50\%) were newly referred and 42 (50\%) were patients evaluated earlier from July 1979 to December 1994, and being followed in the author's own clinical practice of adult patients. All patients in this study had serological samples collected sequentially with no exclusions or refusals; all were obtained from ambulatory patients.

For each patient, the age and year of the initial diagnosis of either ulcerative colitis or Crohn's disease along with the clinical findings in each patient were recorded. This included site and extent of disease in the upper and lower gastrointestinal tracts, presence or absence of histologically defined granuloma, intestinal and extraintestinal complications including perianal disease, medical and surgical therapies, familial history of documented IBD and definition of postsurgical complications, including pouchitis in patients who had undergone a restorative pelvic pouch procedure after proctocolectomy for ulcerative colitis.

Laboratory studies: For each patient, all blood samples were collected into vacutainer glass tubes (Becton Dickinson, Franklin, New Jersey) by a laboratory technologist without knowledge of the patient's clinical history, investigation results or diagnosis. Blood was also obtained for hematological studies (hemoglobin, white blood cell count and platelet count), erythrocyte sedimentation rate, antinuclear antibodies, liver chemistry tests (aspartate aminotransferase, alanine aminotransferase and alkaline phosphatase), serum iron studies and serum protein tests, including serum albumin.

Finally, blood samples were collected into vacutainer glass tubes, allowed to clot at room temperature and used for detection of ANCA via two methods: ANCA immunofluorescence and ELISA. Serological studies for ANCA were done by a single laboratory technologist blinded to the clinical details and diagnosis. If ANCA immunofluoresence was positive, ANCA ELISA was done for autoantibodies to myeloperoxidase (MPO) and serine protease-3 (PR-3).

ANCA immunofluorescence: Indirect immunofluorescence for c-ANCA, p-ANCA and atypical p-ANCA was detected with a standardized fluorescent antibody detection method $(2,8)$, using a proprietary kit purchased from a commercial supplier (Inova Diagnostics Inc, San Diego, California). Slides were supplied with an adherent layer of cultured human neutrophils. The culture conditions were designed to ensure stability and strong expression of the primary cytoplasmic granules. The adherent neutrophils were fixed by the manufacturer with either ethanol or formalin. The primary screen for $\mathrm{c}$-ANCA or $\mathrm{p}$-ANCA involved incubation of se- 
rum at a one to 20 dilution in phosphate-buffered saline with ethanol-fixed slides for 25 mins at room temperature followed by a $5 \mathrm{~min}$ wash with phosphate-buffered saline. This was followed by another 25 min incubation using affinity-purified antihuman immunoglobulin (Ig) $\mathrm{G}$ with a fluorescent tag and a further 5 min wash with phosphate-buffered saline. Coverslips were then applied to the slides, and these were examined with a fluorescence microscope at $\times 500$ magnification.

Positive ANCA cellular fluorescence was recorded and the distribution patterns of fluorescence designated as c-ANCA, $p$-ANCA or atypical p-ANCA. Sera that were positive for either $p$-ANCA or atypical $p$-ANCA were further evaluated using formalin-fixed slides because formalin destroys nuclear antigens and atypical p-ANCA. In addition, formalin fixes both c-ANCA and p-ANCA antigens in the cytoplasm so that a false positive pattern is not observed. Antinuclear antibody-positive sera were excluded because these may mimic ANCA.

ELISA assays: ANCA ELISA assays were performed with a standardized method $(2,8)$ using commercial kits (Quanta-Lite MPO and PR-3 ELISA, Inova Diagnostics Inc). The test kits use microtitration strips containing wells coated with either PR-3, a primary antigen related to the c-ANCA pattern, or MPO, a primary antigen associated with the p-ANCA pattern. Diluted serum was applied and incubated. If specific antibodies are present, they bind to the wells. Unbound material is initially removed by washing, and bound antibody is detected by adding enzyme-labelled antihuman $\mathrm{IgG}$, followed by a second washing, then incubated with a nitrophenol substrate. Wells with PR-3 or MPO antibodies are quantified by a colorimetric method.

\section{RESULTS}

Patient population: In this prospectively studied population cohort of Indo-Canadians residing in the metropolitan area of Vancouver, a clinical diagnosis of ulcerative colitis was established in 62 of 84 patients (almost 75\%) with IBD; the other 22 patients had Crohn's disease (Table 1). This distribution contrasts with the results of a prospectively studied population of 500 patients that included 247 patients with ulcerative colitis and 253 with Crohn's disease (2), as well as with studies of the Chinese population of Vancouver with either ulcerative colitis (9) or Crohn's disease (10). This disease-based predominance of ulcerative colitis versus Crohn's disease was present in the patients born in Canada as well as in migrants to Canada from other countries, including India (Table 2).

For patients with either Crohn's disease or ulcerative colitis, the percentages born in Canada (36\% versus 34\%, respectively) appeared to be similar. All migrants from other countries developed IBD after residing in Canada. The duration of residence in Canada before diagnosis was shorter for patients with Crohn's disease (mean 8.9 years, range two to 25) than for those with ulcerative colitis (mean 13.5 years, range three to 28).

The mean age at diagnosis of IBD was 32.5 years. How-
TABLE 1

Characteristics of an Indo-Canadian cohort with inflammatory bowel disease $(n=84)$

\begin{tabular}{|c|c|c|}
\hline & $C D(n=22)$ & UC $(n=62)$ \\
\hline Age (mean years) & 28.8 & 33.8 \\
\hline Sex, male (\%) & $11(50)$ & $35(56)$ \\
\hline Period followed (mean years) & 5.9 & 5.5 \\
\hline Born in Canada (\%) & $8(36)$ & $21(34)$ \\
\hline Lived in Canada (mean years) & 8.9 & 13.5 \\
\hline \multicolumn{3}{|l|}{ Site } \\
\hline Small bowel (\%) & $6(27)$ & 0 \\
\hline Large bowel (\%)* & $8(36)$ & $62(100)$ \\
\hline Both $(\%)$ & $8(36)$ & 0 \\
\hline Granuloma (\%) & $10(45)$ & 0 \\
\hline Fistula/abscess (\%) & $5(23)$ & 0 \\
\hline \multicolumn{3}{|l|}{ ANCA status ${ }^{\dagger}$} \\
\hline Positive (\%) & $7(32)$ & $33(53)$ \\
\hline Negative (\%) & $15(68)$ & $29(47)$ \\
\hline Cytoplasmic ANCA (\%) & $3(14)$ & $5(8)$ \\
\hline \multicolumn{3}{|l|}{ Medication(s) ${ }^{\star}$} \\
\hline 5-Acetylsalicylic acid only (\%) & $4(18)$ & $23(37)$ \\
\hline Steroids $(\%)$ & $17(77)$ & $38(61)$ \\
\hline Immunosuppressant (\%) & $2(9)$ & $9(15)$ \\
\hline Metronidazole (\%) & $10(45)$ & $7(11)$ \\
\hline Nutritional support (\%) & $4(18)$ & $3(5)$ \\
\hline \multicolumn{3}{|l|}{ Confirmed family history } \\
\hline CD alone (\%) & $4(18)$ & $1(2)$ \\
\hline UC alone (\%) & 0 & $5(8)$ \\
\hline Both CD and UC (\%) & $2(9)$ & 0 \\
\hline One family member & $2(9)$ & $4(6)$ \\
\hline Multiple members & $4(18)$ & $2(3)$ \\
\hline \multicolumn{3}{|l|}{ Surgery } \\
\hline Resection & $7(32)$ & $6(10)$ \\
\hline Pelvic pouch & 0 & $5(8)$ \\
\hline Other & 1 stricturoplasty & 0 \\
\hline \multicolumn{3}{|l|}{ Complications } \\
\hline Autoimmune complications & $2(9)$ & $4(6)$ \\
\hline Pouchitis & 0 & $3(5)$ \\
\hline Colonic neoplasm & 0 & $2(3)$ \\
\hline Drug allergy & $3(14)$ & $2(3)$ \\
\hline Other & $2(9)$ & $2(3)$ \\
\hline
\end{tabular}

*For ulcerative colitis (UC): distal colitis 30 (48\%) and extensive colitis 32 (52\%); ${ }^{\dagger}$ Positive or negative for all types of antineutrophil cytoplasmic autoantibodies (ANCA) (note that positive usually refers to atypical perinuclear ANCA; however, cytoplasmic ANCA were present in eight of 84 Indo- Canadians); ${ }^{*}$ For some patients, more than one medication was used. CD Crohn's disease

ever, the mean age for Crohn's disease patients (28.8 years) was significantly less than that for ulcerative colitis patients (33.8 years) $(\mathrm{P}<0.05)$ (Table 1$)$. Moreover, for all patients with IBD (Table 2), the mean age at diagnosis for those born in Canada $(21.7$ years) was significantly less $(\mathrm{P}<0.05)$ than that for the migrant populations (ie, born in India 41.0 years; born in other countries including East African countries 34.6 years). 
TABLE 2

Birthplace of members of an Indo-Canadian cohort and characteristics of inflammatory bowel disease $(n=84)$

\begin{tabular}{lccc}
\hline & \multicolumn{3}{c}{ Birthplace } \\
& $\begin{array}{c}\text { Canada } \\
(\mathbf{n = 2 9 )}\end{array}$ & $\begin{array}{c}\text { India } \\
(\mathbf{n = 3 1 )}\end{array}$ & $\begin{array}{c}\text { Other* } \\
(\mathbf{n = 2 4 )}\end{array}$ \\
\hline Age (mean years) & 21.7 & 41.0 & 34.6 \\
Sex, male (\%) & $17(59)$ & $16(52)$ & $14(58)$ \\
Crohn's disease (\%) & $8(28)$ & $6(19)$ & $8(33)$ \\
Ulcerative colitis (\%) & $21(72)$ & $25(81)$ & $16(67)$ \\
ANCA status ${ }^{\dagger}$ & & & $12(50)$ \\
\multicolumn{1}{c}{ Positive (\%) } & $13(45)$ & $18(58)$ & $12(50)$ \\
$\quad$ Negative (\%) & $16(55)$ & $13(42)$ & $3(13)$ \\
$\quad$ Cytoplasmic ANCA (\%) & $4(14)$ & $1(3)$ &
\end{tabular}

*Other included East African countries, particularly Uganda, and the Fiji Islands; ${ }^{\dagger}$ Positive or negative for all types of antineutrophil cytoplasmic autoantibodies (ANCA) (note that positive usually refers to atypical perinuclear ANCA; however, cytoplasmic ANCA were present in eight of 84 Indo-Canadians)

For patients with either Crohn's disease or ulcerative colitis, there was a preponderance of males. This male-predominant sex distribution was present for each group despite country of birth. Sex did not appear to influence mean age of diagnosis for Crohn's disease (females 28.2 years, males 30.0 years) or ulcerative colitis (females 33.6 years, males 33.8 years).

Disease types and characteristics: For Indo-Canadians with Crohn's disease, the percentages of patients with disease limited to the small bowel alone (27\%), large bowel alone $(36 \%)$, or both small and large bowel $(36 \%)$ were similar. This prominence of 'colon only' disease in Indo-Canadians with Crohn's disease differs from the more typical site distribution of other patients in the author's hospital (2). For ulcerative colitis, similar numbers of patients had either distal disease $(30[48 \%])$ or more extensive colitis $(32$ [52\%]) in contrast to the slight predominance of distal disease reported in the previous prospective study (2). Pathological changes that included granulomas and the presence of fistulae or abscesses were detected only in patients with Crohn's disease in this study and not in patients with ulcerative colitis.

No Indo-Canadian patient was observed during the course of this study with ischemic colitis, pseudomembranous colitis or a microscopic form of colitis, such as collagenous colitis or lymphocytic colitis (4).

Treatment and complications: Medications included 5. aminosalicylates, steroids and immunosuppressants as well as antimicrobial agents. In most patients, more than one medication was administered during the course of their treatment, particularly for Crohn's disease. For both groups, most were treated with corticosteroids and/or immunosuppressants during a mean follow-up period of five to six years. Some differences were also evident. The proportion of patients who received only a 5 -aminosalicylate $(37 \%)$ was greater in the ulcerative colitis group than in the Crohn's disease group $(18 \%)$, while use of metronidazole was more frequent in pa- tients with Crohn's disease (45\%) than in those with ulcerative colitis (11\%). More Indo-Canadians with Crohn's disease required parenteral nutrition during their disease course than those with ulcerative colitis, and a greater proportion of patients with Crohn's disease required surgical treatment (32\%). Only six patients (about 10\%) with a diagnosis of ulcerative colitis required colectomy; of these, five had a pelvic pouch reconstructive procedure. To date, $60 \%$ of these patients have developed pouchitis. Finally, two patients with ulcerative colitis had colonic neoplasms detected; both were tubular adenomas and both were endoscopically resected. So far, no other dysplastic lesions or colon cancer has been detected in these 84 patients.

In Table 1, extraintestinal ('autoimmune') complications are noted. These were uncommon in this population, ie, six of $84(7 \%)$. Of note, five patients experienced dermatological reactions to 5-aminosalicylates that resolved with cessation of the medications.

Confirmed family history: A family history of IBD was defined as endoscopic and histological confirmation of disease in parents or siblings. For patients with Crohn's disease, six of $22(27 \%)$ had a family member with IBD, usually Crohn's disease. For patients with ulcerative colitis, six of $62(10 \%)$ had a family member with IBD, usually with ulcerative colitis. For both diseases, single or multiple family members were diagnosed. No family member residing outside of Canada had IBD or colon carcinoma.

ANCA: Overall, 40 of 84 (47.6\%) were seropositive for ANCA; this was higher than the $38.8 \%$ rate in a previous prospective study of 500 patients (2). A majority of ulcerative colitis patients and a minority of Crohn's disease patients were seropositive (53.2\% and $31.8 \%$, respectively; $\mathrm{P}<0.05$ ); these results differed from earlier detection rates (ulcerative colitis $66.3 \%$, Crohn's disease $11.9 \%$ ). Interestingly, positive cytoplasmic staining (c-ANCA) was present in eight patients (or about 10\%) compared with the overall estimated frequency of $2 \%$ in patients with IBD (6).

Table 3 summarizes the results for 84 seropositive and seronegative Indo-Canadian patients with IBD based solely on their ANCA status; mean ages for seropositive (31.1 years) and seronegative patients ( 30.5 years) were similar. In addition, about equal percentages of males and females were present in both groups. Moreover, the number of patients born in Canada was similar to the number of migrants to Canada. Finally, mean periods of residence in Canada before development of IBD for seropositive and seronegative migrant patients were similar.

Most seropositive patients had inflammatory disease in the large intestine (93\%), but seropositive patients were also detected with disease localized only in the small intestine or in both sites. Similarly, most seronegative patients also had disease in the large intestine alone (75\%) compared with the small intestine alone or both sites. Thus, in contrast to an earlier report from Los Angeles, California (11), the definition of seropositive status was not sufficient in this study to indicate that the inflammatory disease was localized only to the colon and not present in the small intestine. 
The presence or absence of most complications would not have been defined by ANCA status, including pouchitis (Table 3). Interestingly, however, seropositive patients in this small Indo-Canadian cohort with IBD appeared to be protected from fistulizing disease or abscesses.

\section{DISCUSSION}

The most striking finding in this study was the overall, about three to one, preponderance of patients with ulcerative colitis versus Crohn's disease. This is consistent with observations for South Asian immigrants in the United Kingdom (12). In the latter report, adults from two hospitals (East Birmingham Hospital, the Bradford Royal Infirmary) and children (St Bartholomew's Hospital) had a similar diagnosis ratio (three to one) for ulcerative colitis versus Crohn's disease. This was also observed in an epidemiological evaluation of South Asians residing in Leicestershire, United Kingdom (13), where 134 South Asians with ulcerative colitis and 31 with Crohn's disease were seen. The present study also extended these findings to individual subgroups of Indo-Canadians, including those born in Canada as well as different migrant groups. Interestingly, this increased ratio of ulcerative colitis to Crohn's disease was not observed in a sequentially evaluated non-Indian patient group with IBD from our hospital (2). Although these studies have not evaluated all Indo-Canadians with IBD in Vancouver and only involved a cohort from a single referral practice, the present findings suggest that patients of South Asian descent in Canada are at greater risk for the development of ulcerative colitis than of Crohn's disease. These findings are consistent with the view that both diseases arise in individuals with a genetic predisposition but apparently only after exposure to some, as yet unknown, environmental factor.

Another finding in the present study was the significantly younger mean age of patients born in Canada than of those from other countries, particularly India. This geographically based difference in mean ages was seen in both ulcerative colitis and Crohn's disease patients, suggesting that the expression of the disease may depend on environmental factors following migration and residence in Canada. For patients with ulcerative colitis, this period of residence in Canada was longer (about 13.5 years) than for patients with Crohn's disease (about 8.9 years). This raises the possibility that different periods of time may be required for the clinical expression of either ulcerative colitis or Crohn's disease.

Studies from India on ulcerative colitis have been limited (14-17). Most have shown a male predominance, often with clinically mild disease restricted to the left colon (17). These results differ from those of a large tertiary care-based studies in North America that suggest more severe disease (18). In the present study, a male predominance was noted for Indo-Canadians born in Canada as well as for the migrant groups. Clinically, moderate to severe disease was suggested by the high frequent requirement for corticosteroids and/or immunosuppressants for either Crohn's disease or ulcerative colitis patients, limited numbers of patients controlled with 5-aminosalicyates alone, frequent hospitalizations for nutri-
TABLE 3

Characteristics of Indo-Canadians with antinuclear cytoplasmic autoantibody (ANCA) -positive and -negative inflammatory bowel disease* $(n=84)$

\begin{tabular}{|c|c|c|}
\hline & $\begin{array}{c}\text { Positive } \\
(n=40)\end{array}$ & $\begin{array}{c}\text { Negative } \\
(n=44)\end{array}$ \\
\hline Age (mean years) & 31.1 & 30.5 \\
\hline Sex, male (\%) & $19(48)$ & $26(59)$ \\
\hline Period followed (years) & 5.1 & 5.4 \\
\hline Born in Canada (\%) & $11(28)$ & $10(23)$ \\
\hline Lived in Canada (years) & 16.2 & 14.4 \\
\hline \multicolumn{3}{|l|}{ Site } \\
\hline Small bowel (\%) & $1(3)$ & $5(11)$ \\
\hline Large bowel (\%) & $37(93)$ & $33(75)$ \\
\hline Both $(\%)$ & $2(5)$ & $6(14)$ \\
\hline Granuloma (\%) & $3(8)$ & $6(14)$ \\
\hline Fistula/abscess (\%) & $0(0)$ & $5(11)$ \\
\hline \multicolumn{3}{|l|}{ Medication $^{\dagger}$} \\
\hline 5-Acetylsalicylic acid only (\%) & $12(30)$ & $15(34)$ \\
\hline Steroids $(\%)$ & $29(73)$ & $26(59)$ \\
\hline Immunosuppressant (\%) & $6(15)$ & $5(11)$ \\
\hline Metronidazole (\%) & $5(13)$ & $12(27)$ \\
\hline Nutritional support (\%) & $3(8)$ & $4(9)$ \\
\hline \multicolumn{3}{|l|}{ Family history } \\
\hline CD alone (\%) & $2(5)$ & $3(7)$ \\
\hline UC alone (\%) & $3(8)$ & $2(5)$ \\
\hline Both CD and UC (\%) & 0 & $2(5)$ \\
\hline One family member & $3(8)$ & $3(7)$ \\
\hline Multiple members & $2(5)$ & $4(9)$ \\
\hline \multicolumn{3}{|l|}{ Surgery } \\
\hline Resection & $4(10)$ & $9(20)$ \\
\hline Pelvic pouch & $3(8)$ & $2(5)$ \\
\hline Other & 0 & 1 stricturoplasty \\
\hline \multicolumn{3}{|l|}{ Complications } \\
\hline Autoimmune complications & $3(8)$ & $3(7)$ \\
\hline Pouchitis & $2(5)$ & $1(2)$ \\
\hline Colon neoplasm & none & $2(5)$ \\
\hline Drug allergy & $2(5)$ & $3(7)$ \\
\hline Other & 0 & $4(9)$ \\
\hline
\end{tabular}

*All types of neutrophil cytoplasmic antibodies; ${ }^{\dagger}$ For some patients, more than one medication was used. CD Crohn's disease; UC Ulcerative colitis

tional support and/or surgical therapy, and frequent and often extensive colonic disease, particularly in patients with ulcerative colitis.

This study also compared and contrasted patients with and without serologically detected ANCA. Almost $50 \%$ of the patients in the present study were seropositive, higher than the proportion found in previous study of 500 patients from this centre $(38.8 \%)$ (2), but very different from that found in a recent North Indian study that noted a very low seropositive rate of $3 \%$ in ulcerative colitis (19). While methodological differences may be possible, the precise reason for these different detection rates is not known. The patient and disease characteristics in the present study cohort 
from Vancouver were very similar to observations in Asian-Indians with ulcerative colitis from New Delhi (19). For both, there was a male predominance (Vancouver $56 \%$, New Delhi 53\%), and mean age at diagnosis was in the fourth decade (Vancouver 33.8 years, New Delhi 37.3 years). Both were tertiary centre-based studies, and disease severity was considered moderate or severe with a slight predominance of more extensive colitis (Vancouver 52\%, New Delhi 59\%). Although more extraintestinal 'autoimmune' complications were described in this recent Indian study than in the present study, an earlier investigation from the same area for 200 ulcerative colitis patients reported a rate of $3 \%$ (20), probably reflecting different reporting definitions.

Other differences in reported ANCA patterns were also evident. In the New Delhi study, only p-ANCA were de-

\section{REFERENCES}

1. Saxon A, Shanahan F, Landers C, Ganz T, Targan S. A subset of antineutrophil anticytoplasmic antibodies is associated with inflammatory bowel disease. J Allergy Clin Immunol 1990;86:202-10.

2. Freeman H, Roeck B, Devine D, Carter C. Prospective evaluation of neutrophil autoantibodies in 500 consecutive patients with inflammatory bowel disease. Can J Gastroenterol 1997;11:203-7.

3. Freeman HJ, Roeck B, Devine DV, Carter CJ. Atypical perinuclear antineutrophil cytoplasmic antibodies after colectomy in inflammatory bowel disease. Can J Gastroenterol 1997;11:305-10.

4. Freeman HJ. Perinuclear antineutrophil cytoplasmic antibodies in collagenous or lymphocytic colitis with or without celiac disease. Can J Gastroenterol 1997;11:417-20.

5. Freeman HJ. Atypical perinuclear antineutrophil cytoplasmic antibodies in patients with Crohn's disease. Can J Gastroenterol 1997;11:689-93.

6. Freeman HJ. Inflammatory bowel disease with cytoplasmic-staining antineutrophil cytoplasmic antibody and extensive colitis. Can J Gastroenterol 1998;12:279-82.

7. Lennard-Jones JE. Classification of inflammatory bowel disease. Scand J Gastroenterol Suppl 1989;170:2-6.

8. Duerr RH, Targan SR, Landers CJ, Sutherland LR, Shanahan F. Neutrophil autoantibodies in ulcerative colitis. Comparison with other colitides/diarrheal diseases. Gastroenterology 1991;100:1385-91.

9. Chaun H, Freeman HJ. Ulcerative colitis in the Chinese population of Vancouver, British Columbia. Can J Gastroenterol 1994;8:303-7.

10. Chaun H, Freeman HJ. Crohn's disease in Chinese in Vancouver, Canada. Can J Gastroenterol 1993;7:28-32. scribed. In the present study, cytoplasmic staining, c-ANCA, was also seen in eight of 84 (approximately 10\%) patients, all with extensive colitis. This is significantly higher than the previously estimated frequency of this seromarker in approximately $2 \%$ of patients with IBD.

Further studies in the Indo-Canadian population of Vancouver will be helpful to define the precise prevalence of both ulcerative colitis and Crohn's disease in this population compared with other groups, including other migrant populations. The predominance of ulcerative colitis compared with Crohn's disease and the rarity, to date, of literature descriptions of specific inflammatory intestinal diseases, including the microscopic colitides (lymphocytic colitis, collagenous colitis), in Indian populations, require further elucidation.

11. Vasiliauskas EA, Plevy SE, Landers CJ, Targan SR. Perinuclear antineutrophil cytoplasmic antibodies in patients with Crohn's disease define a clinical subgroup. Gastroenterology 1996;110:1810-9.

12. Walker-Smith JA, Benfield GFA, Montgomery RD, et al. Chronic inflammatory bowel disease in immigrants in the United Kingdom. Front Gastrointest Res 1986;11:118-34.

13. Probert CSJ, Jayanthi V, Hughes AO, Thompson JR, Wicks ACB, Mayberry JF. Prevalence and family risk of ulcerative colitis and Crohn's disease: an epidemiologic study among Europeans and South Asians in Leicestershire. Gut 1993;34:1547-51.

14. Tandon BN, Mathur AK, Mohapatra LN. A study of the prevalence and clinical pattern of non-specific ulcerative colitis in Northern India. Gut 1965;6:448-53.

15. Chuttani HK, Nigam S, Sama SK. Ulcerative colitis in the tropics. Br Med J 1967;iv:204-7.

16. Antia FP, Kairo RH, Gandhi MK. Ulcerative colitis: its prevalence in socioeconomic groups. Indian J Gastroenterol 1985;4:19-20.

17. Kapur P, Aggarwal SK, Prakash P. Idiopathic ulcerative colitis in Northern India. Indian J Gastroenterol 1986;5:247-58.

18. Farmer RG, Easley LA, Rankin GB. Clinical patterns, natural history, and progression of ulcerative colitis: a long-term follow-up of 1116 patients. Dig Dis Sci 1993;38:1137-46.

19. Habeeb MA, Rajalingam R, Dhar A, Kumar A, Sharma MP, Mehra NK. HLA association and occurrence of autoantibodies in Asian-Indian patients with ulcerative colitis. Am J Gastroenterol 1997;92:772-6.

20. Sharma MP, Sarin SK. Ulcerative colitis in a North Indian hospital: current trends. J R Coll Physicians Lond 1985;19:99-102. 


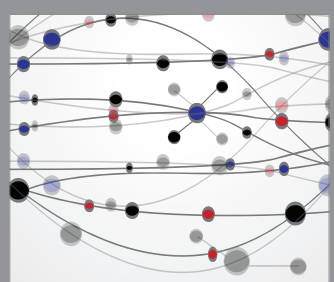

The Scientific World Journal
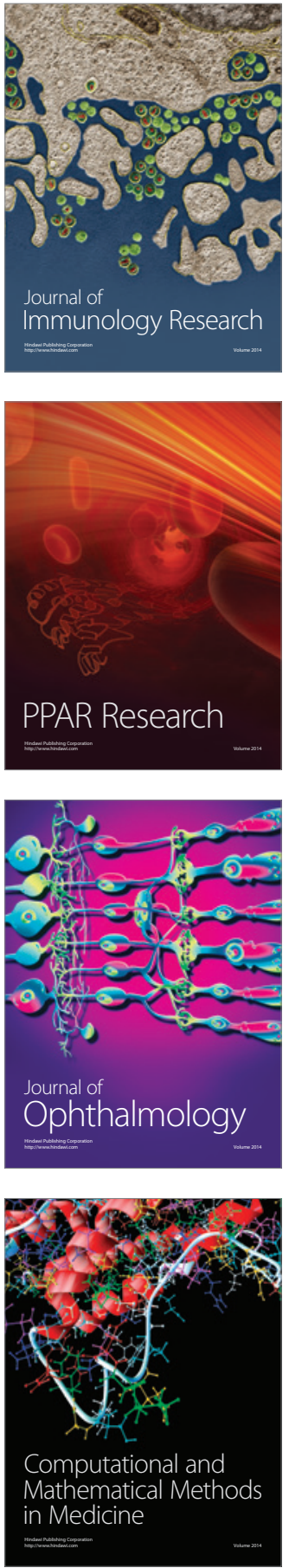

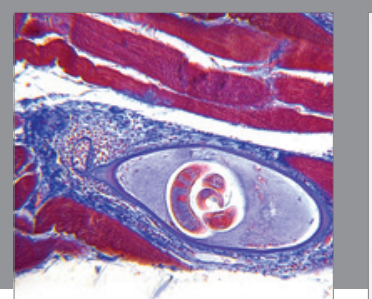

Gastroenterology Research and Practice

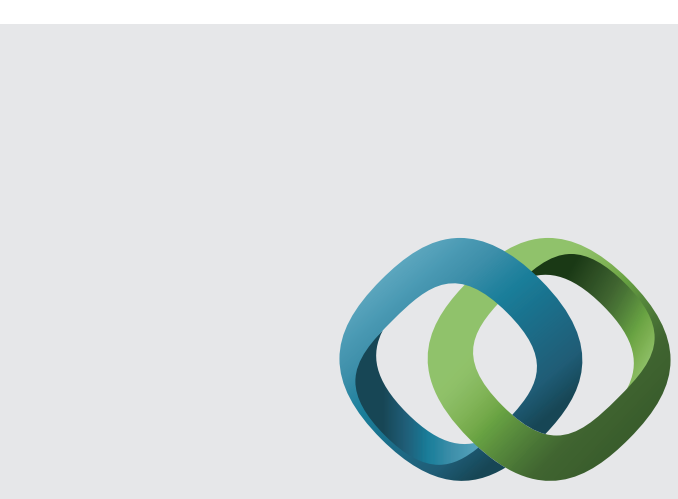

\section{Hindawi}

Submit your manuscripts at

http://www.hindawi.com
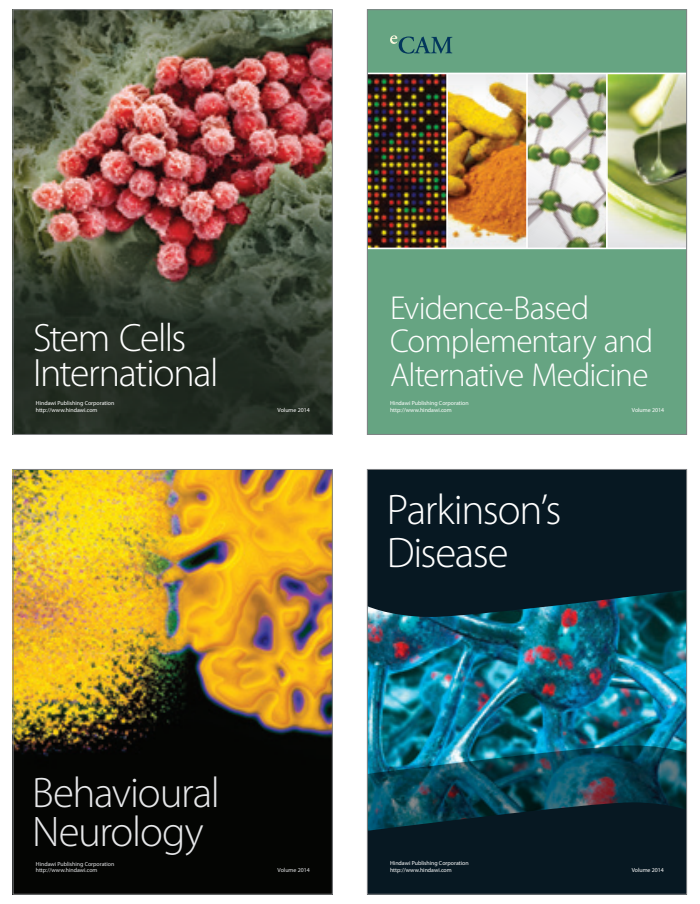
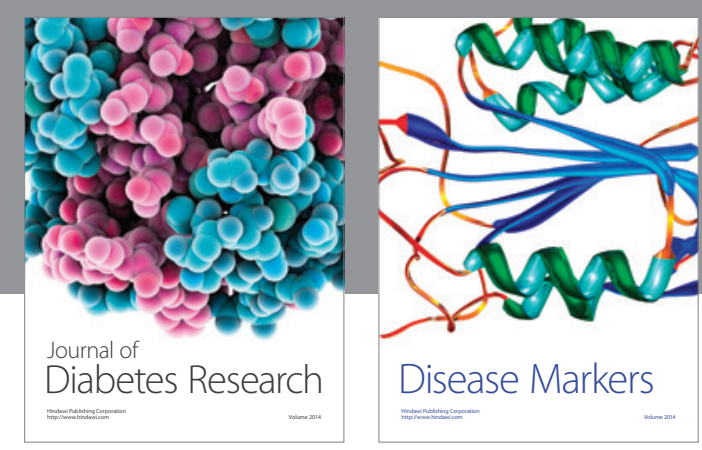

Disease Markers
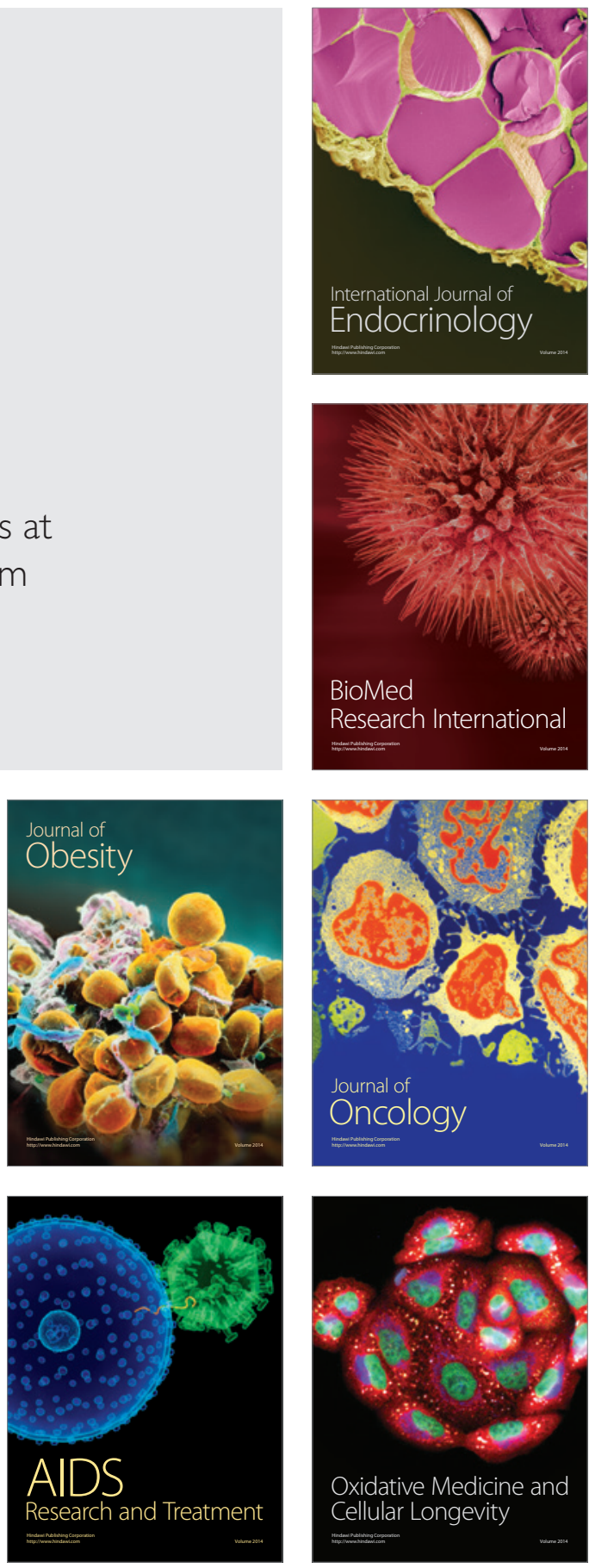